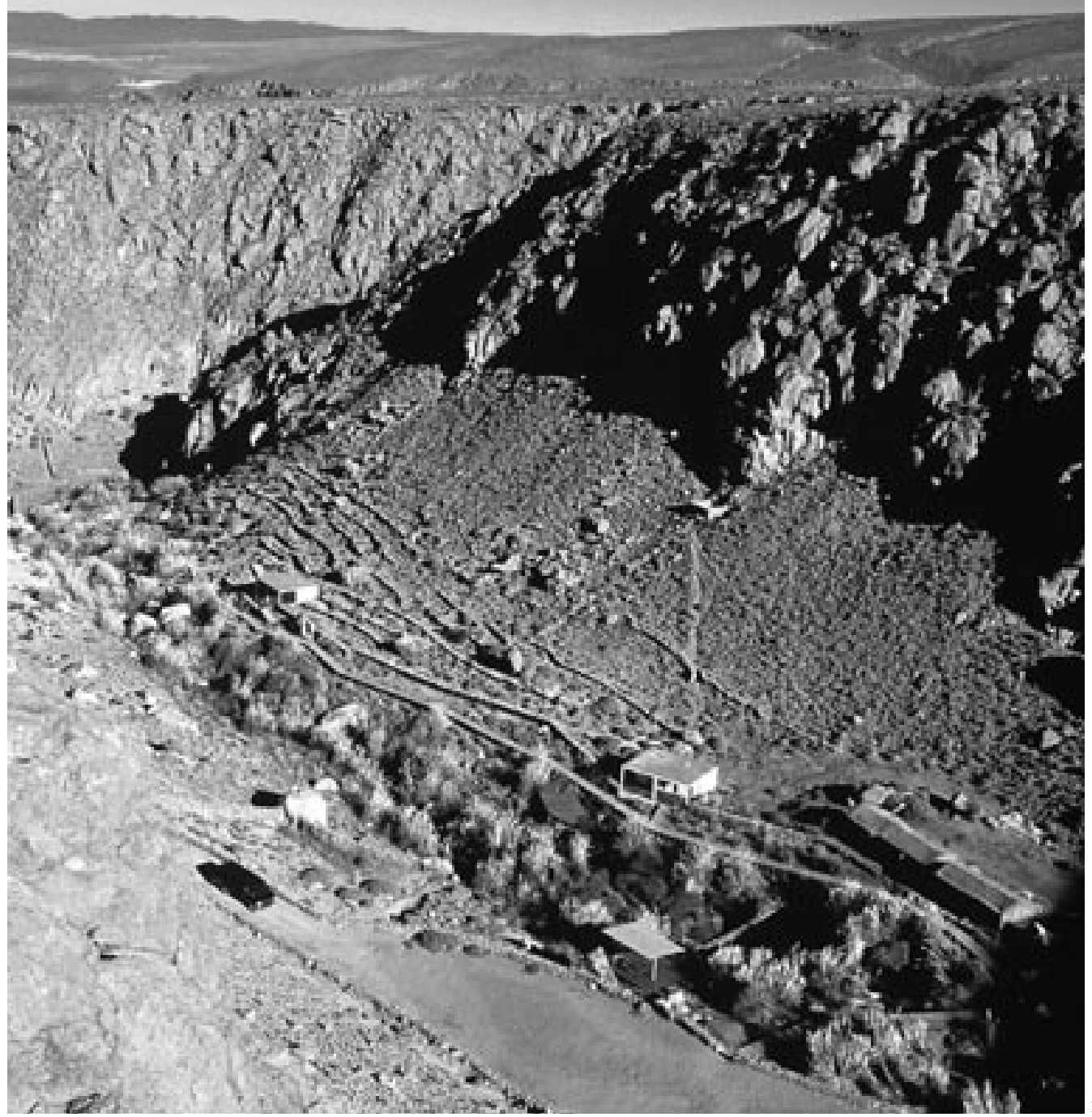

Germán Del Sol

San Pedro de Atacama, Chile

La presencia excepcional del agua en el desierto chileno en este caso no es asumida como un recurso productivo para la agricultura. Un manantial termal ha posibilitado ancestralmente el recreo: esta intervención intenta cuidar la condición primaria y dulce de este suelo excepcionalmente búmedo, para el juego y descanso de lugareños y visitantes. Palabras clave: Arquitectura - Chile, paisajismo - Chile, zonas áridas, termas, Palabras clave: Arquitectura - Chile, paisajismo -

A rare source of water in the Chilean desert, this thermal spring has not been harnessed as a productive resource for agriculture. Instead, it has been used since ancient times for recreation. This intervention attempts to maintain the soft and primitive condition of the exceptionally bumid soil as a place of rest and leisure for locals as well as visitors. Key words: Architecture-Chile, landscaping-Chile, arid zones, spas, therma springs, Puritan $A$

\title{
Termas de Puritama
}

Las termas de Puritama están un fundo de 60.000 hectáreas que compramos para Explora, con la idea de preservar el lugar con obras mínimas de mejora, apoyo y "saneamiento", para luego entregarlas en administración al Consejo de los Pueblos Atacameños que cuida el lugar como lo hacía antiguamente, y que recibe los ingresos que se generan por el cobro de entrada. (El Consejo en una época me pidió asesoría, y yo les propuse entre otras cosas que se hicieran cargo de la administración de los lugares arqueológicos, una riqueza enorme de los atacameños que hasta entonces estaba inexplicablemente a cargo de CONAF).

El río termal fluye generosamente en un valle escondido a $60 \mathrm{~km}$ de San Pedro de Atacama en Chile. Recorre unos $14 \mathrm{~km}$ antes de encontrarse con el río Purifica, un poco mas bajo de Guatín. La terma ocupa más de un kilómetro de la quebrada del río Puritama, que corre desde la cordillera aguas abajo, a partir del punto donde afloran las aguas termales.

El río crea en su cauce sinuoso muchos pozones naturales, que se usan para bañarse desde tiempo inmemorial.
Los pozones se han ampliado en todo sentido, para darle una cierta plenitud al puro hecho de bañarse en una terma en una quebrada en medio del desierto. Esta arquitectura en el paisaje intenta darle esplendor al lugar, mostrándolo poéticamente y hacer posible el uso sustentable de las piscinas termales naturales, creando ingresos para la comunidad local.

El muelle de madera levantado del suelo invita a seguir el curso sinuoso del río, y a dispersarse entre los pozones sin pisar el pasto y los arbustos, que crecen en la orilla.

Dos estructuras neutras de hormigón armado suavizado con yeso pintado de blanco, alojan todos los servicios necesarios. Son signos de vida que revelan la naturaleza brutal del lugar.

\section{El color de la madera y el color en Atacama} Las pasarelas son de madera impregnada, teñida de rojo sin tapar la veta, formando un filtro contra los rayos ultravioleta que en Atacama destruyen más que la pudrición por hongos (que no hay) o las termitas (que tampoco hay).

Aquí, como en otras obras, nos hemos jugado por 


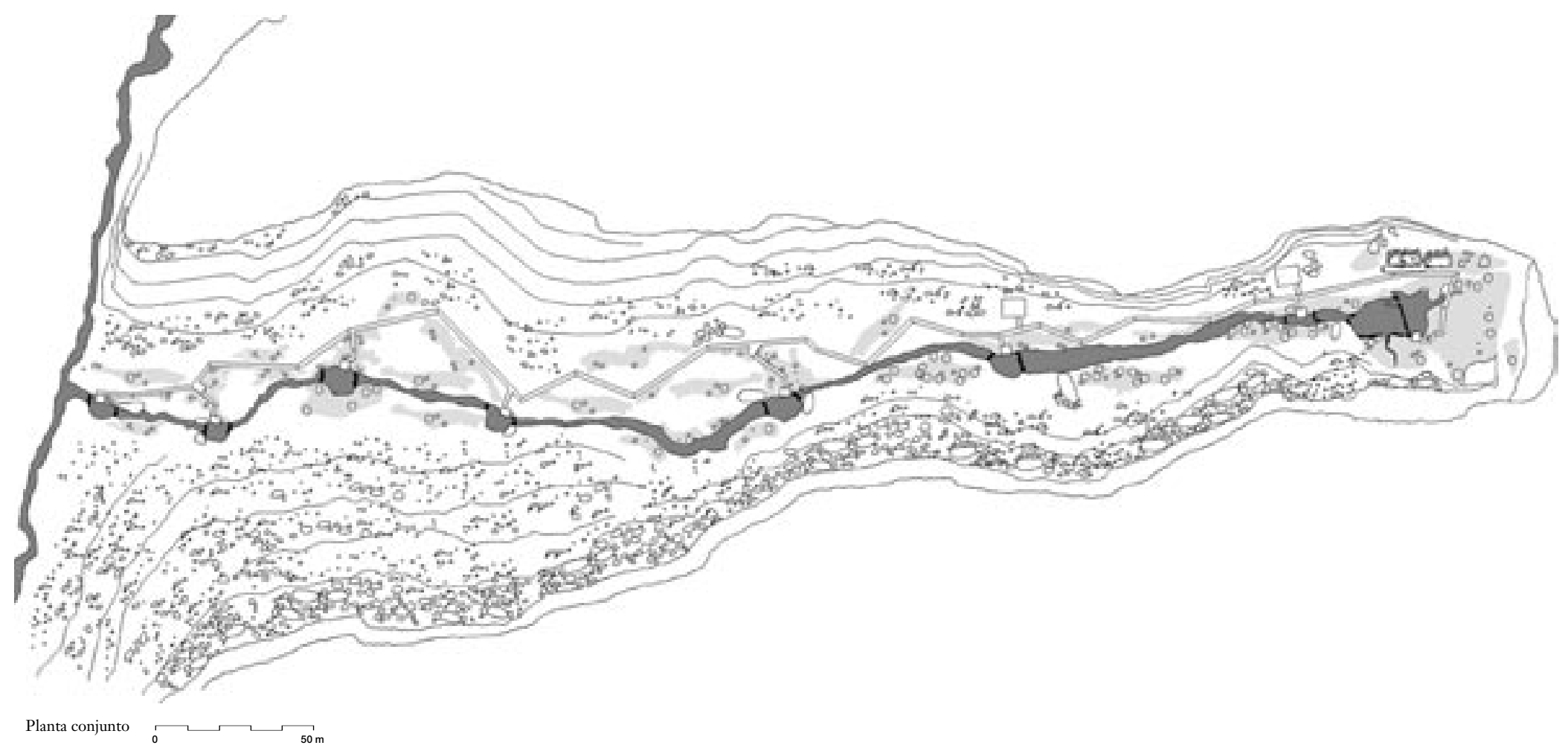

captar la atmósfera de Atacama con sus toques desordenados de color y sus formas imprecisas y temblorosas.

Nos parece que en la cultura atacameña el color son todos los colores: se usan separados y se juntan en "el aire". Un "impresionismo" espacial en un ambiente de color neutro y que a plena luz del sol no vibra si no hay color. Afuera hay mucho contraste entre luz y sombra; adentro hay imprevistos vibraciones de un color con otro. Colores dispuestos con libertad en un orden suelto, pero con ojo único o común.

Nos parece que en Atacama el color como signo de vida está en los objetos cotidianos: por supuesto en la ropa en las marcas de los animales, y en las partes de la arquitectura que se tocan. En las puertas, ventanas, parrones, sillas, asientos, mesas, etc.

La luz penetrante de los descampados de Atacama crea un medio ambiente de arena que todo iguala y donde a mi juicio, el color es signo evidente de vida, (probablemente porque no hay flores) y el rojo como único color, con que pintan las cuevas, es signo de la presencia de vida humana, que acompaña e invita a detenerse. ARQ

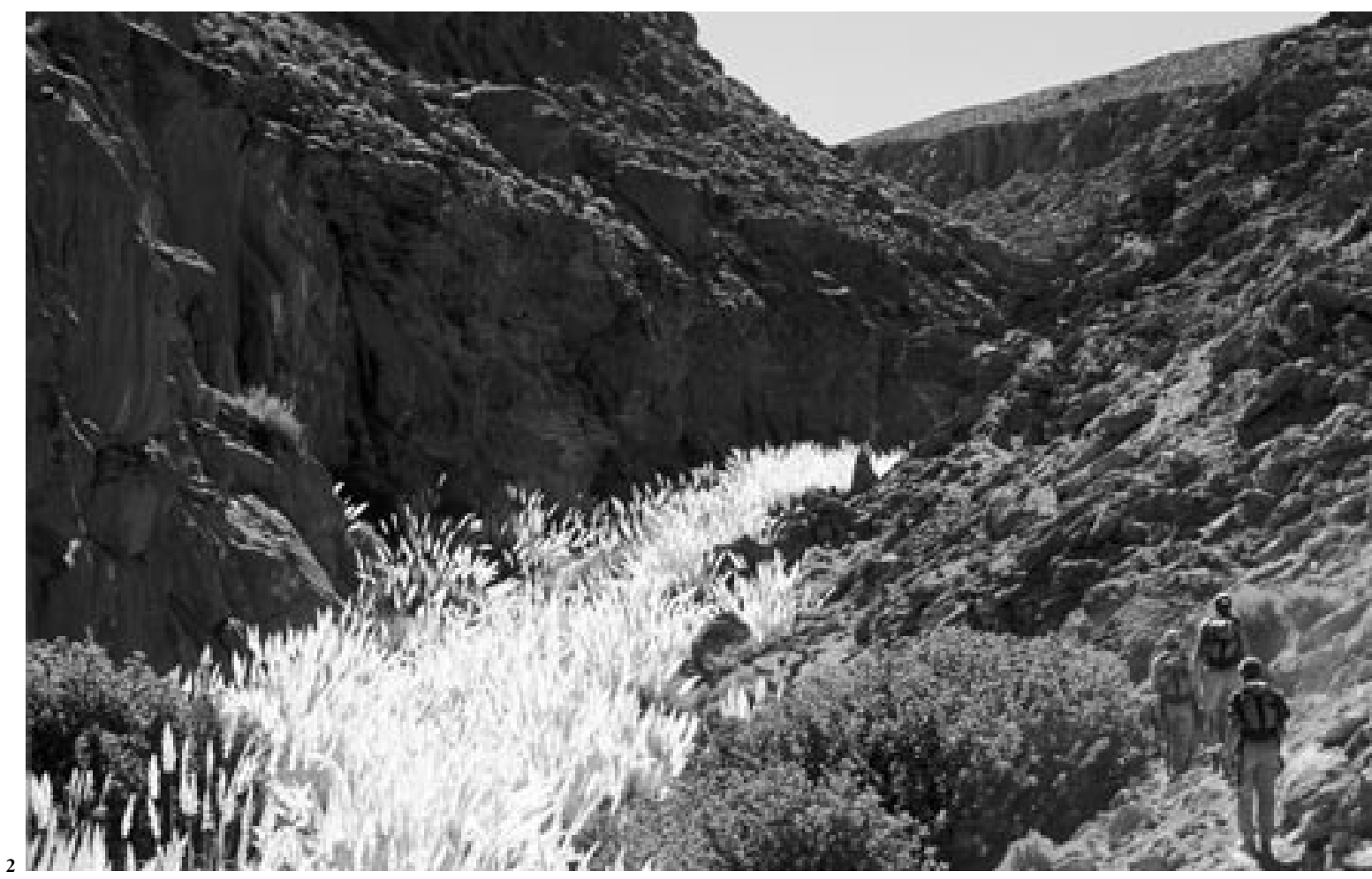



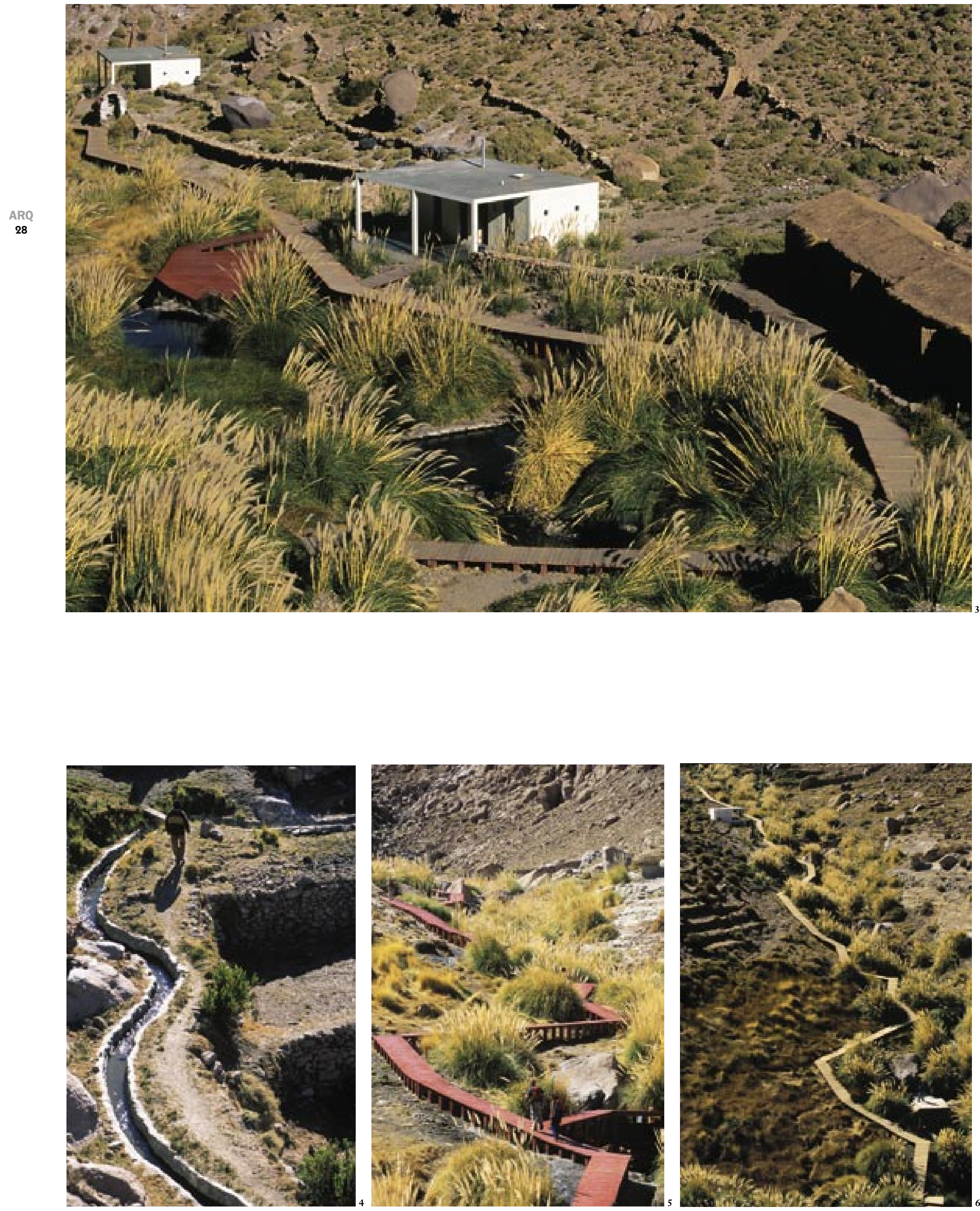

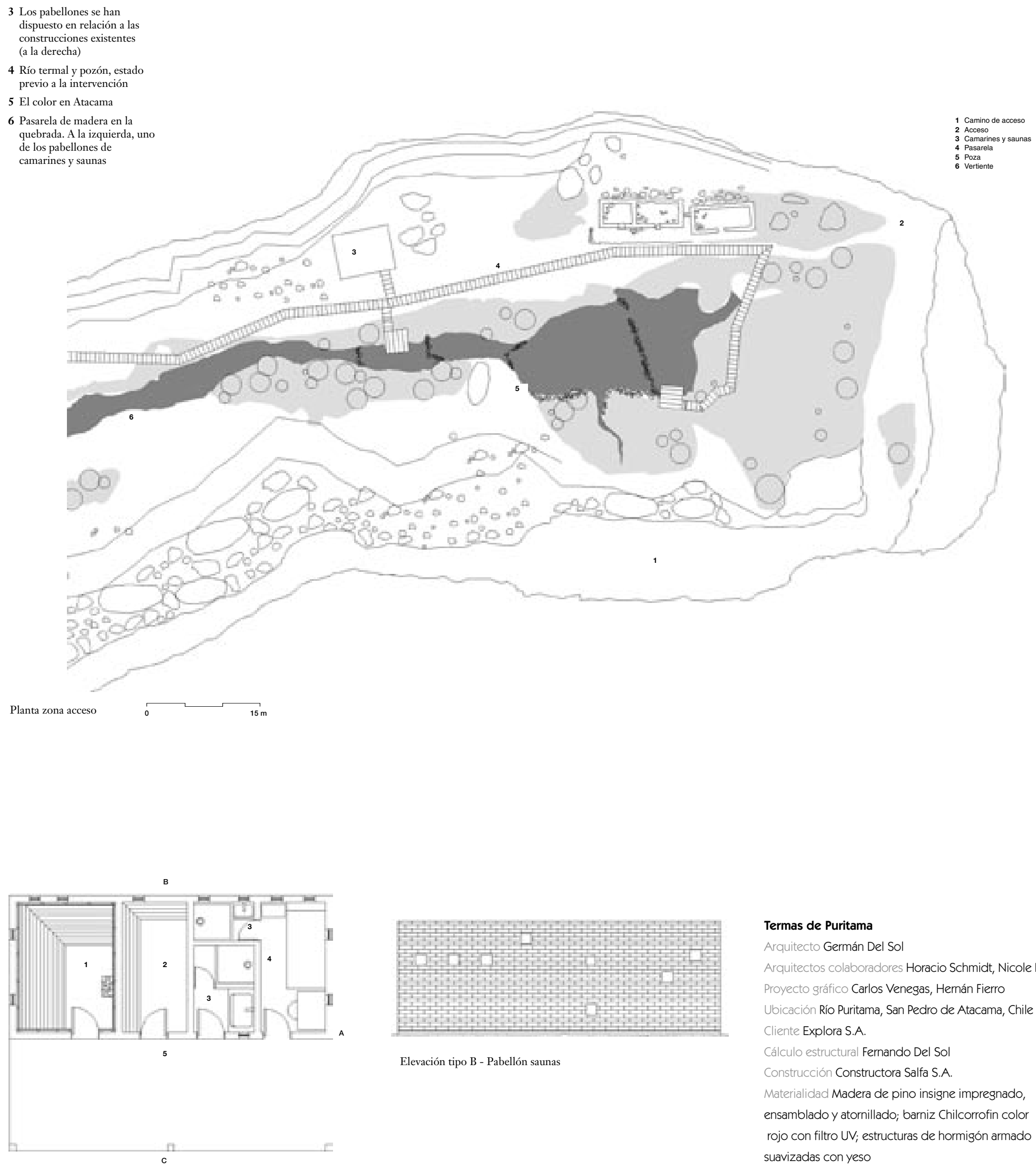

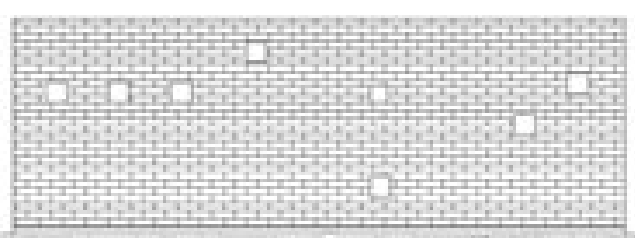

Elevación tipo B - Pabellón saunas

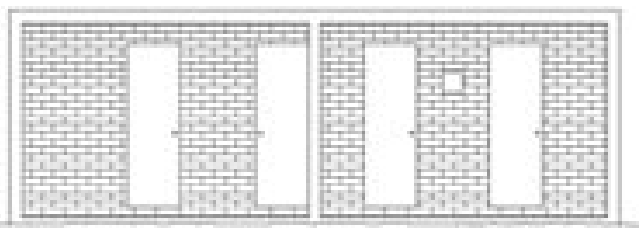

Elevación tipo C - Pabellón saunas

\section{Termas de Puritama}

Arquitecto Germán Del Sol

Arquitectos colaboradores Horacio Schmidt, Nicole Labbé Proyecto gráfico Carlos Venegas, Hernán Fierro Ubicación Río Puritama, San Pedro de Atacama, Chile Cliente Explora S.A.

Cálculo estructural Fernando Del Sol Construcción Constructora Salfa S.A.

Materialidad Madera de pino insigne impresnado, ensamblado y atornillado; barniz Chilcorrofin color rojo con filtro UV; estructuras de hormigón armado suavizadas con yeso

Presupuesto obra 20.600 UF estimado (US\$ 538.500) Superficie terreno 60.00 ha

Superficie construida $88 \mathrm{~m}^{2}$ (pabellones),

$752 \mathrm{~m}^{2}$ de pasarelas

Año proyecto 1998 - 2000

Año construcción 1998 - 2000

Fotografía Guy Wenborne 